\section{Sleep duration and health status self-assessment (SF-36) in the elderly: a population-based study (ISA-Camp 2008)}

\author{
Duração do sono e estado de saúde autorreferido \\ (SF-36) em idosos: estudo de base populacional \\ (ISA-Camp 2008)
}

Margareth Guimarães Lima 1 Marilisa Berti de Azevedo Barros 1 Maria Cecília Goi Porto Alves 2

\section{Introduction}

The aim of this study was to determine the association between sleep duration and health status among the elderly. A population-based study was carried out with 1,418 elderly individuals using data from the health survey of Campinas, São Paulo State, Brazil (ISA-Camp 2008). Linear regression models were used to determine associations between the physical and mental components and subscales of the SF-36 and sleep duration. Elderly male individuals who slept $\leq 6$ hours obtained lower mean SF-36 scores for the vitality and mental health scales and the mental component summary than those who slept for seven to eight hours. All scales were negatively associated with sleep duration $\geq 10$ hours, except bodily pain. Scores for the mental health, vitality and role-emotional subscales were lower among women who slept for less than five hours. Mental health was negatively associated with $\geq 10$ hours of sleep. Sleep deprivation and excessive sleep were associated with poorer health status, with differences between genders, principally in the long duration sleep categories.

Quality of Life; Sleep; Health of the Elderly; Health Status
Health status and health-related quality of life can be self-assessed using the 36-item ShortForm Health Survey (SF-36). This instrument assesses different dimensions of health in individuals or populations such as the physical, emotional and social aspects of quality of life, bodily pain, mental health, vitality and general health 1. A number of studies report a strong correlation between the health dimensions addressed by the SF-36 and the presence of health conditions and clinical symptoms 2,3 and also suggest that self-assessment may serve to predict mortality ${ }^{4}$. The measurement of health status dimensions provides useful indicators of health conditions and wellbeing that may complement evaluations of illness and mortality indicators 1,5 .

An association has been reported between sleep duration under 7 to 8 hours (considered the medium sleep duration pattern of sleep) and an increase in mortality from all causes 6,7 , in addition to a greater prevalence of diseases such as diabetes 8 , hypertension ${ }^{9}$, depression ${ }^{10}$, rheumatic disease, osteoporosis 11 and obesity 12,13. Literature also suggests that good quality sleep provides for daily recovery from physical and mental stresses, improves mood, concentration and memory and reduces the risk of accidents $8,14,15$. 
Among the elderly population, sleep duration patterns and prevalence of sleep disorders differ between genders. Elderly men tend to sleep more $8,16,17$, take longer to fall asleep and remain in bed longer 8 , whereas elderly women experience a longer rapid eye movement phase 8 in spite of the tendency toward a greater frequency of sleep disorders, especially insomnia and restless legs syndrome 18,19 . Although scarce, studies on the relationship between sleep duration and mortality and gender in the elderly have shown that risk of death increases with longer sleep patterns in men 20 and with shorter sleep patterns in women 17,21.

It is also reported that demographic and socioeconomic factors and health-related behavioral factors are associated with sleep duration. The percentage of men that maintain a sleep duration pattern of seven to eight hours is greater than in women. Individuals who do not work tend to sleep more. Higher levels of education and income are associated with a greater frequency of a medium sleep pattern 12,22. Marital status, racial differences 23,24 and health-related behavior 22 are associated with sleep duration. Krueger \& Friedman 22 found that an increase in physical activity reduces the likelihood of sleeping 9 or more hours. The prevalence of a medium sleep pattern is greater in non-smokers, whereas excessive alcohol intake is associated with short sleeppatterns 22 .

Little is known regarding the association between self-assessed health status and sleep duration. Research addressing this topic includes a study by Faubel et al. 25 who administered the SF-36 to elderly individuals in Spain. Other studies concerning this association that did not employ the SF-36 were also found 26,27,28 and two studies exist regarding this relationship in students 26,27. Other investigations have assessed the relationship between health status and sleep disorders 29,30,31.

To help fill this knowledge gap regarding sleep and self-assessed health status in the elderly population, the aim of the present study was to analyze the association between sleep duration and a number of different health dimensions among elderly residents of the city of Campinas, São Paulo State, Brazil.

\section{Materials and methods}

A population-based, cross-sectional study was conducted using data from the City of Campinas Health Survey (ISA-Camp) of the urban population aged 10 years and over in Campinas, carried out in 2008 and 2009.
The ISA-Camp survey was performed in two stages involving census sectors and households. In the first stage, 50 census tracts were selected with probability proportional to the number of households. The census tracts were ordered according to the percentage of heads of households holding a university education prior to the systematic sampling. Sample size was determined considering an estimated proportion of 0.50 (maximal variability in the events studied) with a $95 \%$ confidence interval $(95 \% \mathrm{CI})$, four to five percentage point sampling error and a design effect of 2. A total of 1,000 individuals in each age group (adolescents aged 10 to 19 years; adults aged 20 to 59 years and elderly individuals aged 60 years and over) that should have been selected was increased to 1,250 to compensate for possible losses.

The number of households selected for each age group was determined using the ratio between the desired sample size and the mean number of individuals per household in each specific age group, using the Census 2000 data (http://www. ibge.gov.br). A total of 2,150 households were randomly selected for adolescents, 700 for adults and 3,900 for elderly individuals. After concluding the field survey of the selected sectors for the purpose of updating addresses, the households were randomly selected in a systematic fashion. In each household, only those individuals in the target age group were interviewed.

With respect to the group elderly individuals aged 60 years and over, the present study only analyzed data of those individuals who self-administered the questionnaire and answered the question on sleep duration, totaling 1,418 individuals. Information on the variables was obtained using a previously tested structured questionnaire administered by trained, supervised interviewers.

The dependent variables were based on the SF-36 questionnaire (version 2), which measures self-assessed health status and is made up of 36 items distributed among eight subscales: physical functioning, role-physical, bodily pain, general health status, vitality, role-emotional, social aspects and mental health. The SF-36 also allows for the assessmentof the subscales summarized in the physical component summary (physical functioning, role-physical and bodily pain) and mental component summary (role-emotional, social aspects and mental health). General health state and vitality are present in both components 1,32 . Version 1 of the questionnaire was translated and validated for use in Brazil by Ciconelli et al. 33, while Laguardia et al. 34 validated version 2 . The present study was licensed by the International Quality of Life Assessment (IQOLA) project that documents the use of the SF-36. 
In this study, scoring of each SF-36 subscale followed the method proposed in the literature 1 . For version 2, standardized scoring is suggested normalized to the population of the United States or of the country in which the study is being conducted. As there are no normalized scores for Brazil, the decision was made to use non-standardized scores. However, the two components were constructed based on the standard for international comparison purposes using standardization established for the general population of the United States (mean: 50; standard deviation: 10), as recommended by the researchers who drafted the SF-36 1,32.

The main independent variable was based on the following question: "How long do you sleep for on average on weekdays and weekend days?". Answers were noted separately for weekdays and weekend days. For weekdays the response was multiplied by five and for weekend days the response was multiplied by two to calculate the weighted mean number of hours and minutes of sleep. For females, the following sleep duration categories were used: 5 or fewer hours, 6 hours, 7 to 8 hours, 9 hours and 10 or more hours. For males, the $\leq 5$ and 6 -hour categories were combined due to the small number of men who reported sleeping 5 or fewer hours. Analysis was performed separately for men and women, considering the reported association between gender and sleep duration 16,22 and the strong association between gender and health status in the elderly $35,36,37$.

The following variables were incorporated into the regression analyses: age (continual variable); level of schooling ( 0 to 3,4 to 8,9 or more years of study); number of self-reported chronic diseases (hypertension, diabetes, heart disease, cancer, rheumatism/arthritis/arthrosis, osteoporosis, respiratory problems, repetitive strain injury, circulation problems, emotional problems / anxiety/depression, headache/migraine, back problems, allergy, dizziness), categorized as no diseases, 1, 2, 3, 4 and 5 or more diseases; physical activity during leisure time (non-active, insufficiently active, active); smoking (never smoked, ex-smoker, smoker); and alcohol intake (never, less than once a week, once a week or more). These variables were used to reflect associations between sleep duration and health status reported in previous studies 2,22,38,39.

Categorical variables were transformed into dummy variables in order to determine the beta coefficients of each category of variables. Analysis was conducted with multiple linear regression in order to test associations between dependent variables and the main independent variable, with adjustments for confounding vari- ables. A regression model was created for each of the eight subscales and the two components of the SF-36. Results with a p-value $<0.05$ were considered statistically significant. Analysis was performed using svy commands of the Stata 11.0 program (Stata Corp., College Station, USA), taking into account the complex sample design of the study (design variables were the sampling units selected in the first stage and the weight of the sample elements).

This study received approval from the Ethics Research Committee of the School of Medical Sciences, of the State University of Campinas (Faculdade de Ciências Médicas, Universidade Estadual de Campinas - Unicamp), Brazil (no 079/2007).

\section{Results}

A loss of $14.2 \%$ occurred among the elderly sample $(6.1 \%$ refusal rate, $3.1 \%$ of the individuals were not at home and $5.0 \%$ for other reasons). Among the elderly individuals found at home, there was a $5.5 \%$ refusal rate and a loss rate of $6.9 \%$ for other reasons. Individuals who did not answer the self-administered questionnaire and the question on sleep duration were excluded $(n=96)$. As a result of the above selection, a total of 1,418 individuals aged 60 years and over (mean age: 69.5 years; $95 \%$ CI: 68.8-70.1) were analyzed. Mean age was 68.8 years (95\%CI: 68.1-69.5) for men and 70.0 years (95\%CI: 69.2-70.8) for women. Women accounted for $56.9 \%$ (95\%CI: 54.4-59.4) of the overall sample.

Table 1 shows that $32.4 \%$ of men and $20.4 \%$ of women had nine or more years of schooling and the percentage of women with a monthly income of four times the minimum salary was less than in men. The prevalence of five or more chronic diseases was greater in women than in men. The percentage of men sleeping ten or more hours was greater than in women. Mean SF-36 version 2 scores were higher among men for the physical component summary, mental component summary and each of the subscales, except for general health. After adjusting for age, the role-physical scale lost its statistical significance (Table 2).

Table 3 displays the mean scores for sleep duration in the male population. After adjusting for age, Model 1 revealed that, among elderly men, the mean vitality $(\beta=-8.6)$, mental health ( $\beta=-8.3$ ), and mental component summary ( $\beta=-3.9$ ) scores were lower in individuals who slept for six or fewer hours than in those who slept for seven to eight hours. Mean scores for the mental component summary and mental health scale $(\beta=-4.3)$ were lower in individuals who slept 
Demographic and socioeconomic characteristics, health status and sleep duration of the elderly population, according to gender. ISA-Camp 2008, Campinas, São Paulo State, Brazil.

\begin{tabular}{|c|c|c|c|c|c|c|c|}
\hline \multirow[t]{2}{*}{ Variable } & \multicolumn{2}{|r|}{ Men } & \multicolumn{2}{|r|}{ Women } & \multicolumn{2}{|r|}{ Total } & \multirow[t]{2}{*}{$\mathrm{p}$-value ** } \\
\hline & $\mathbf{n}$ & $\%$ * & $\mathrm{n}$ & $\%$ * & $\mathrm{n}$ & $\%$ * & \\
\hline Age (years) & & & & & & & 0.1181 \\
\hline $60-69$ & 337 & $58.5(53.2-62.7)$ & 455 & $53.8(48.8-58.8)$ & 792 & $55.8(52.0-59.6)$ & \\
\hline $70-79$ & 184 & $31.7(28.2-35.1)$ & 280 & $33.4(30.0-36.7)$ & 464 & $32.7(30.1-35.2)$ & \\
\hline 80 and over & 56 & $09.8(06.8-12.7)$ & 106 & $12.8(09.5-15.9)$ & 162 & $11.5(08.8-14.1)$ & \\
\hline Total & 577 & 100.0 & 841 & 100.0 & 1,418 & 100.0 & \\
\hline Level of schooling (in years) & & & & & & & $<0.0001$ \\
\hline $0-3$ & 167 & $28.1(21.0-35.0)$ & 331 & $38.5(31.4-45.4)$ & 498 & $34.0(27.4-40.5)$ & \\
\hline $4-8$ & 232 & $39.5(33.6-45.4)$ & 347 & $41.1(36.5-45.7)$ & 579 & $40.4(35.9-44.9)$ & \\
\hline 9 and more & 178 & $32.4(23.2-41.6)$ & 162 & $20.4(14.5-26.2)$ & 340 & $25.6(18.6-32.4)$ & \\
\hline $\begin{array}{l}\text { Per capita monthly income (number of } \\
\text { minimum wages) }\end{array}$ & & & & & & & 0.0001 \\
\hline$<1$ & 217 & $36.8(30.0-43.5)$ & 357 & $41.7(35.7-47.6)$ & 574 & $39.6(33.5-45.6)$ & \\
\hline $1-3$ & 226 & $38.7(33.6-45.4)$ & 349 & $41.3(37.3-45.2)$ & 575 & $40,2(36.2-44.1)$ & \\
\hline$\geq 4$ & 134 & $24.5(23.2-41.6)$ & 135 & $17.0(11.2-22.6)$ & 269 & $20.2(14.2-26.2)$ & \\
\hline Number of chronic disease & & & & & & & $<0.0001$ \\
\hline None & 72 & $13.7(10.5-16.8)$ & 63 & $07.7(05.1-10.0)$ & 141 & $10.3(07.9-12.5)$ & \\
\hline $1-2$ & 241 & $42.1(36.5-47.5)$ & 202 & $24.4(19.6-29.2)$ & 443 & $32.0(27.8-36.2)$ & \\
\hline $3-4$ & 151 & $26.3(22.5-30.1)$ & 263 & $32.0(28.5-35.4)$ & 414 & $29.6(26.9-32.2)$ & \\
\hline$\geq 5$ & 103 & $17.9(14.3-21.3)$ & 297 & $35.9(30.4-41.4)$ & 400 & $28.1(23.8-32.3)$ & \\
\hline Sleep duration (hours) & & & & & & & 0.0016 \\
\hline$\leq 5$ & 34 & $05.8(03.4-08.1)$ & 80 & $09.6(06.8-12.2)$ & 114 & $07.9(05.8-10.0)$ & \\
\hline 6 & 69 & $12.3(08.8-15.7)$ & 108 & $12.9(09.9-15.9)$ & 177 & $12.7(09.9-15.3)$ & \\
\hline $7-8$ & 318 & $55.0(49.4-60.6)$ & 477 & $56.8(51.9-61.6)$ & 795 & $56.0(51.4-60.6)$ & \\
\hline 9 & 78 & 13.5 (09.8-17.1) & 112 & $13.1(10.3-15.9)$ & 190 & $13.3(10.6-15.9)$ & \\
\hline$\geq 10$ & 78 & $13.4(10.3-16.3)$ & 64 & $07.6(05.6-09.4)$ & 142 & $10.1(08.8-12.0)$ & \\
\hline
\end{tabular}

* Weighted percentages considering the sample design;

** $\mathrm{p}$-value result of chi-squared test, based on Pearson's design.

for nine hours than in those who slept for seven to eight hours. All scales and both components of the SF-36 were negatively associated with ten or more hours of sleep. The greatest differences were found for role-physical $(\beta=-21.9)$, roleemotional ( $\beta=-18.5$ ) and physical functioning ( $\beta=-18.2)$. After adjusting for schooling, number of chronic diseases and health-related behavior (physical activity during leisure, smoking and alcohol intake), all associations established in the Model 1 remained significant, with the exception of mental health and the mental component summary in the nine-hour sleep category and bodily pain in the ten-hour sleep category.

Table 4 displays the mean SF-36 scores according to sleep duration shorter or longer than seven to eight hours (beta coefficients, results of linear regression) for the female population.
Model 1 reveals that scores for the bodily pain scale $(\beta=-7.8)$ and mental component summary ( $\beta=-5.7)$, as well as for the subscales that made up this component (vitality, role-emotional and mental health) were lower in elderly women who slept five or less hours. Four of the eight SF-36 subscales were negatively associated with ten or more hours of sleep (physical functioning, rolephysical, vitality and mental health) as well the physical component summary. Model 2 revealed that five or less hours of sleep was negatively associated with the mental component summaryand the mental health, vitality and role-emotional scales. Mean scores for the mental health subscales were lower in women who slept for ten or more hours. 
Table 2

Mean and standard error of the SF-36 version 2 scale scores and the physical component summary and mental component summary in the general elderly population and by gender. ISA-Camp 2008, Campinas, São Paulo State, Brazil.

\begin{tabular}{|c|c|c|c|c|c|c|c|}
\hline SF-36 version 2 scales & Women (1) & $\begin{array}{l}\text { Mean (SE) } \\
\text { Men (2) }\end{array}$ & Total & $\begin{array}{c}\text { Crude } \\
\text { differences }\end{array}$ & $\begin{array}{c}\text { p-value ** } \\
(2 / 1)\end{array}$ & $\begin{array}{c}\text { Adjusted } \\
\text { differences }(\beta) \\
\star(2 / 1)\end{array}$ & $\begin{array}{c}\text { p-value ** } \\
(2 / 1)\end{array}$ \\
\hline Physical functioning & $71.4(1.39)$ & $80.1(1.42)$ & $75.2(1.11)$ & -8.7 & $<0.001$ & -7.7 & $<0.001$ \\
\hline Role-physical & 76.9 (1.39) & $81.2(1.44)$ & 78.7 (1.10) & -4.3 & 0.018 & -3.5 & 0.057 \\
\hline Bodily pain & $71.6(1.12)$ & $80.7(1.06)$ & $75.6(0.83)$ & -9.1 & $<0.001$ & -8.7 & $<0.001$ \\
\hline General health & $71.6(1.08)$ & $73.3(1.05)$ & $72.3(0.95)$ & -1.7 & 0.076 & -1.5 & 0.092 \\
\hline Vitality & $69.9(1.47)$ & $75.5(1.47)$ & $72.3(1.34)$ & -5.6 & $<0.001$ & -5.3 & $<0.001$ \\
\hline Role-emotional & $85.5(1.10)$ & $90.0(0.94)$ & $87.4(0.80)$ & -4.5 & 0.001 & -4.0 & 0.004 \\
\hline Social functioning & $81.6(1.34)$ & $85.5(1.34)$ & $83.3(1.11)$ & -3.9 & 0.011 & -3.4 & 0.031 \\
\hline Mental health & $75.9(1.13)$ & $80.3(1.09)$ & $77.8(0.98)$ & -4.4 & $<0.001$ & -4.2 & $<0.001$ \\
\hline 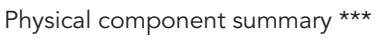 & $45.9(0.47)$ & $48.5(0.49)$ & $47.0(0.38)$ & -2.6 & $<0.001$ & -2.3 & $<0.001$ \\
\hline Mental component summary \# & $53.3(0.49)$ & $59.4(0.49)$ & $54.0(0.41)$ & -6.1 & 0.007 & -1.5 & 0.008 \\
\hline
\end{tabular}

SF-36: 36-item Short-Form Health Survey.

* Mean differences (beta coefficients resulting from liner regression model adjusted by age);

** $\mathrm{p}$-value resulting from linear regression $\mathrm{t}$ test;

*** Physical component summary: comprising physical functioning, role-physical, bodily pain, general health and vitality scales;

\# Mental component summary: comprising general health, vitality, role-emotional, social functioning and mental scales.

\section{Discussion}

In the present study, $56.0 \%$ (95\%CI: 50.9-59.6) of elderly individuals maintained a seven to eighthour sleep duration pattern $(17.6 \%$ slept for seven hours and $38.4 \%$ slept for eight hours). A total of $20.6 \%$ (95\%CI: 16.4-23.4) slept for six or fewer hours and 23.4\% (95\%CI: 21.1-28.4) slept for nine or more hours. Another study carried out in Brazil involving 1,512 elderly individuals found a $26.1 \%$ and $20.6 \%$ frequency for the seven-hour and eight-hour sleeping categories respectively 40 . In the United States, approximately $24 \%$ of individuals aged 65 years and over sleep for six or less hours, whereas $12.4 \%$ sleep for nine or more hours 24 , and $19 \%$ of individuals aged 75 years and over sleep for nine or more hours 24 .

To our knowledge, the present investigation and the study by Falbel et al. 25, carried out in Spain with 3,834 elderly individuals stratified by gender, are the only studies developed to date using the SF-36 to analyze the association between sleep duration and health status in an elderly population.

In the present study, sleep duration under seven to eight hours was associated with poor health status among the elderly individuals, with significant differences between genders and health domains. The categories used to analyze the association between sleep duration and health status are based on those used in studies demonstrating associations with mortality risk and the prevalence of illness 41,42,43. A number of studies,especially those involving elderly individuals, also use the seven to eight-hour sleep duration category as a reference 28,42 , whereas some other studies use the seven-hour category as a reference 25,40 . The present study adopted the seven-hour reference category, leading to similar results.

The association between short sleep duration and poor health status was evident in both genders for the mental component, as well as for the vitality, mental health and role-emotional scale among women. These findings corroborate with those of the literature that show that sleep deprivation is associated with mood, tension and fatigue 14,15 , especially with the advance in age 14 . The study carried out by Faubel et al. 25 found differences in mean SF-36 scores for all scale of the mental component in the adjusted analyses only in women, with a greater magnitude of association for role-emotional scale. Gangwish et al. 44 found that a higher percentage of individuals sleeping $\leq 5$ hours reported depression. The results of one study involving adults in the United States demonstrate that the likelihood of depression/anxiety is greater among those with short sleep duration patterns 22. Besides the association with emotional problems, the relationship 
Beta coefficients of the SF-36 version 2 scale score, physical component summary * and mental component summary ** according to sleep duration in elderly men. ISA-Camp 2008, Campinas, São Paulo State, Brazil.

\begin{tabular}{|c|c|c|c|c|c|c|c|}
\hline \multirow[t]{3}{*}{ SF-36 version 2 scales } & \multicolumn{7}{|c|}{ Sleep duration (hours) } \\
\hline & \multicolumn{2}{|c|}{$\leq 6$} & \multirow{2}{*}{$\begin{array}{c}7 \text { to } 8 \text { (reference) } \\
\text { unadjusted mean (SE) }\end{array}$} & \multicolumn{2}{|c|}{9} & \multicolumn{2}{|c|}{$\geq 10$} \\
\hline & $\beta$ & p-value & & $\beta$ & p-value & $\beta$ & p-value \\
\hline \multicolumn{8}{|l|}{ Model 1} \\
\hline Physical functioning & -1.4 & 0.664 & $83.5(1.17)$ & -0.4 & 0.892 & -18.2 & $<0.001$ \\
\hline Role-physical & -5.3 & 0.182 & $85.7(1.30)$ & -1.3 & 0.693 & -21.9 & $<0.001$ \\
\hline Bodily pain & -3.5 & 0.268 & $84.0(1.09)$ & -5.0 & 0.118 & -12.3 & $<0.001$ \\
\hline General health & -4.2 & 0.090 & $75.9(1.04)$ & -0.9 & 0.666 & -12.7 & $<0.001$ \\
\hline Vitality & -8.6 & 0.001 & $79.5(1.70)$ & -2.7 & 0.317 & -14.7 & $<0.001$ \\
\hline Role-emotional & -4.9 & 0.073 & $93.9(0.83)$ & -2.6 & 0.268 & -18.5 & $<0.001$ \\
\hline Social functioning & -3.8 & 0.198 & $88.8(1.23)$ & -1.0 & 0.696 & -16.5 & $<0.001$ \\
\hline Mental health & -8.3 & 0.003 & $84.8(1.23)$ & -4.3 & 0.013 & -14.6 & $<0.001$ \\
\hline Physical component summary & -0.4 & 0.687 & $49.5(0.44)$ & -0.2 & 0.815 & -5.4 & $<0.001$ \\
\hline Mental component summary & -3.9 & 0.001 & $56.8(0.57)$ & -1.7 & 0.023 & -7.3 & $<0.001$ \\
\hline \multicolumn{8}{|l|}{ Model 2} \\
\hline Physical functioning & 1.6 & 0.540 & $83.5(1.17)$ & 1.7 & 0.579 & -12.5 & $<0.001$ \\
\hline Role-physical & -2.2 & 0.493 & $85.7(1.30)$ & 0.8 & 0.778 & -14.7 & $<0.001$ \\
\hline Bodily pain & -0.8 & 0.775 & $84.0(1.09)$ & -3.1 & 0.310 & -6.2 & 0.052 \\
\hline General health & -1.0 & 0.591 & $75.9(1.04)$ & 1.7 & 0.367 & -6.4 & 0.010 \\
\hline Vitality & -6.4 & 0.009 & $79.5(1.70)$ & -0.5 & 0.841 & -10.1 & $<0.001$ \\
\hline Role-emotional & -2.9 & 0.214 & $93.9(0.83)$ & -1.5 & 0.555 & -13.8 & 0.001 \\
\hline Social functioning & -1.8 & 0.441 & $88.8(1.23)$ & 0.2 & 0.917 & -10.4 & 0.005 \\
\hline Mental health & -6.6 & 0.007 & $84.8(1.23)$ & -2.6 & 0.166 & -11.2 & $<0.001$ \\
\hline Physical component summary & 0.8 & 0.284 & $49.5(0.44)$ & 0.6 & 0.578 & -2.9 & 0.006 \\
\hline Mental component summary & -3.2 & 0.005 & $56.8(0.57)$ & -1.1 & 0.177 & -5.6 & $<0.001$ \\
\hline
\end{tabular}

SF-36: 36-item Short-Form Health Survey.

Model 1: adjusted by age.

Model 2: adjust by age, schooling, number of chronic disease, physical activity during leisure time, smoking and alcohol intake.

* Physical component summary: comprising physical functioning, role-physical, bodily pain, general health and vitality scales;

** Mental component summary: comprising general health, vitality, role emotional, social functioning and mental scales.

between short sleep duration patterns and other health outcomes is also evident. A study involving a representative sample of the population aged 20 years and over in the city of Campinas, revealed an association between greater number of chronic diseases and short sleep duration patterns and no association between the same variable and long sleep duration patterns. The same study also showed that prevalence of rheumatic disease, heart disease, circulation problems, osteoporosis and back pain was higher among adults who sleep $\leq 6$ hours 11. Meta-analysis reveals that short sleep duration patterns and difficulty in initiating and maintaining sleep are predictors for the risk of developing type 2 diabetes 45 . Furthermore, an association has been found between short sleep duration and mortality 6,7.
Although investigations into health status and sleep duration using the SF-36 are few and far between, studies have evidenced an association between sleep problems or sleep disorders and health status. A study carried out in Brazil found that sleeping for six or less hours was strongly associated with poor sleep ${ }^{11}$. According to a study by Wilkelman et al. ${ }^{29}$, elderly individuals with restless legs syndrome obtained worse scores for the vitality and mental health scales and all scales of the mental component summary. Li et al. 30 studied 1,680 elderly individuals aged 60 and over in the Anhui province of China and found that lower vitality and general health were predictors of poor sleep. A 12month follow-up survey involving 185 patients with rheumatic diseases (mean age: 59.4 years) 
Table 4

Beta coefficients of the SF-36 version 2 scale score, physical component summary and mental component summary, according to sleep duration in the elderly women. ISA-Camp 2008, Campinas, São Paulo State, Brazil.

\begin{tabular}{|c|c|c|c|c|c|c|c|c|c|}
\hline \multirow[t]{3}{*}{ SF-36 version 2 scales } & \multicolumn{9}{|c|}{ Sleep duration (hours) } \\
\hline & \multicolumn{2}{|c|}{$\leq \mathbf{5}$} & \multicolumn{2}{|c|}{6} & \multirow{2}{*}{$\begin{array}{c}7 \text { to } 8 \text { (reference) } \\
\text { unadjusted mean (SE) }\end{array}$} & \multicolumn{2}{|c|}{9} & \multicolumn{2}{|c|}{$\geq 10$} \\
\hline & $\beta$ & p-value & $\mathrm{B}$ & p-value & & $\beta$ & p-value & $\beta$ & p-value \\
\hline \multicolumn{10}{|l|}{ Model 1} \\
\hline Physical functioning & -5.7 & 0.205 & -1.2 & 0.621 & $74.4(1.59)$ & -5.2 & 0.068 & -11.5 & 0.012 \\
\hline Role-physical & -5.1 & 0.252 & -0.1 & 0.940 & $78.7(1.42)$ & -0.6 & 0.820 & -9.6 & 0.025 \\
\hline Bodily pain & -7.8 & 0.027 & -0.8 & 0.753 & $73.4(1.39)$ & -1.5 & 0.588 & -5.7 & 0.174 \\
\hline General health & -1.8 & 0.442 & 1.2 & 0.587 & $71.9(1.08)$ & 0.1 & 0.958 & -3.4 & 0.192 \\
\hline Vitality & -8.9 & 0.003 & -2.3 & 0.305 & $71.7(1.56)$ & -0.1 & 0.935 & -6.9 & 0.022 \\
\hline Role-emotional & -8.4 & 0.004 & -0.4 & 0.985 & $87.4(1.07)$ & -1.2 & 0.593 & -7.6 & 0.067 \\
\hline Social functioning & -4.3 & 0.227 & -0.2 & 0.925 & $83.2(1.48)$ & -2.0 & 0.363 & -7.3 & 0.055 \\
\hline Mental health & -13.4 & $<0.001$ & -3.3 & 0.093 & $78.2(1.29)$ & 0.9 & 0.652 & -8.3 & 0.007 \\
\hline Physical component summary & -0.6 & 0.666 & 0.1 & 0.862 & $46.5(0.53)$ & -1.2 & 0.184 & -2.6 & 0.048 \\
\hline Mental component summary & -5.7 & $<0.001$ & -1.0 & 0.321 & $54.2(0.53)$ & 0.4 & 0.585 & -3.3 & 0.058 \\
\hline \multicolumn{10}{|l|}{ Model 2} \\
\hline Physical functioning & -1.4 & 0.716 & 0.4 & 0.861 & $74.4(1.59)$ & -4.0 & 0.108 & -5.6 & 0.201 \\
\hline Role-physical & -0.4 & 0.901 & 0.4 & 0.851 & $78.7(1.42)$ & -0.1 & 0.950 & -6.1 & 0.135 \\
\hline Bodily pain & -3.3 & 0.255 & 0.6 & 0.802 & $73.4(1.39)$ & -1.6 & 0.483 & -0.5 & 0.904 \\
\hline General health & -0.1 & 0.960 & 1.4 & 0.478 & $71.9(1.08)$ & -0.4 & 0.817 & 0.5 & 0.845 \\
\hline Vitality & -5.5 & 0.018 & -1.7 & 0.396 & $71.7(1.56)$ & -0.1 & 0.916 & -4.2 & 0.202 \\
\hline Role-emotional & -6.0 & 0.026 & 0.4 & 0.864 & $87.4(1.07)$ & -0.9 & 0.717 & -4.9 & 0.239 \\
\hline Social functioning & -0.9 & 0.748 & 0.03 & 0.986 & $83.2(1.48)$ & -1.9 & 0.441 & -4.7 & 0.201 \\
\hline Mental health & -9.1 & 0.001 & -3.4 & 0.069 & $78.2(1.29)$ & 0.2 & 0.884 & -5.8 & 0.044 \\
\hline Physical component summary & 0.7 & 0.592 & 0.7 & 0.370 & $46.5(0.53)$ & -1.0 & 0.210 & -0.7 & 0.616 \\
\hline Mental component summary & -4.2 & $<0.001$ & -1.1 & 0.235 & $54.2(0.53)$ & 0.1 & 0.811 & -2.5 & 0.138 \\
\hline
\end{tabular}

SF-36: 36-item Short-Form Health Survey.

Model 1: adjusted by age.

Model 2: adjust by age, schooling, number of chronic disease, physical activity during leisure time, smoking and alcohol intake.

* Physical component summary: comprising physical functioning, role-physical, bodily pain, general health and vitality scales;

** Mental component summary: comprising general health, vitality, role emotional, social functioning and mental scales.

reports lower scores regarding vitality and general health among those with major sleep problems in comparison to those who claimed to have no problems or only mild problems 31 .

Regarding the long sleep pattern, elderly men who slept for ten or more hours a day obtained worse mean scores for all the SF-36 scales, except bodily pain. In the study by Falbel et al. ${ }^{25}$, associations between health status and sleep duration of more than ten hours were only significant in the analysis adjusted for age for all scales, except for the role-emotional scale. Despite the lack of comparative studies, it is possible that work status should be considered as a factor, as reports suggest a greater tendency towards sleep duration patterns of nine or more hours among unemployed individuals 22 . Also, among elderly men, unemployment may lead to lesser social participation and greater isolation, with a reduction in self-esteem, as well as other factors that affect physical and mental health 46 . Long sleep duration patterns seem to play an important role in the relationship with health outcomes and this role is more expressive in men. A study involving 1,842 individuals aged 50 years and over carried out to determine mortality and sleep duration in a Mediterranean population, found that long sleep duration patterns were associated with a high risk of all-cause mortality and strongly associated cardiovascular mortality in men but not in women.

Among women, the association between ten or more hours of sleep and the physical functioning subscale and other scales lost significance 
when adjusted for chronic diseases and other variables, except for mental health.

The relevant results presented in this study were the strong associations between the short sleep with the mental dimension of the elderly in both genders; and long sleep in almost all scales, in men.

The associations between long sleep duration patterns and dimensions of health status among elderly men underscores the need for greater attention to sleep duration patterns among elderly individuals. The presence of disease is an important aspect to consider. In the present investigation, however, the analysis was controlled according to the number of chronic diseases, and individuals with physical or mental conditions were rendered incapable of answering the questionnaire and therefore excluded from the study. In a nine-year follow-up study carried out in Brazil, Castro-Costa et al. 40 found a strong association between all-cause mortality in the case of long sleep duration patterns but not in the case of short sleep patterns.

Knowledge of the association between long sleep duration patterns (more than 9 hours) and health outcomes has only recently come to light and there is a need for further studies in order to gain a better understanding of this association 47 . However, the association between short sleep duration patterns (six or fewer hours) and health is evidenced in epidemiological and laboratory studies 44,47 . More studies are needed to clarify the association between sleep duration and self-assessed health status and other health outcomes.

It should be noted that the present study has certain limitations. The cross-sectional design addresses associations but not their causes and sleep duration may affect the health of elderly individuals or health status may lead to sleep deprivation or excessive sleep.

Although another limitation of the present study was the fact that sleep duration was self-reported, it should be noted that a number of population-based studies have used this type of information 22,44 and other studies have indicated a good correlation between self-reported information and objective sleep measures such as actigraphy 48,49 .

Another limitation regards the fact that the questionnaire did not provide greater details, such as the time taken to fall asleep, time spent in bed, difficulty in initiating and maintaining sleep or for how long an individual maintains his/her sleep pattern. It is also important to consider that stratifying the analysis by gender leads to decreases in the sample size in some sleep categories. However, as the overall sample involved 1,418 elderly individuals, the sample size was sufficient to detect greater than $5 \%$ differences on the SF-36 scales and three points of the components. According to the SF-36 version 2 guide 1, assuming an alpha $=0.05$ and beta $=80 \%$, the sample size needed to detect differences $\geq 5 \%$ varies between 119 and 220 for the mental health and role-physical scales, respectively.

The present study contributes towards a better understanding of the association between sleep duration and different dimensions of selfassessed health status, physical functioning and physical, mental and social wellbeing among the elderly. As the self-assessment of health is significantly associated with clinical conditions and mortality 4,50 , beyond the results of objective measures 5,51, and considers different health dimensions, studies on the association between self-assessed health and sleep duration can provide important information for health management in the elderly. The present study is one of the first to describe this association and broaden knowledge on the relationship between long sleep duration patterns and health outcomes, an area which merits further research.

With the rapid ageing of the population and considerable prevalence of chronic diseases, especially among the elderly, functionality and wellbeing measures are important tools for determining the health profile of this population and can assist in establishing actions aimed at active, healthy ageing. Moreover, understanding the association between sleep duration and selfassessed health status can contribute toward the determination of this profile. 


\section{Resumo}

Avaliar a associação da duração do sono com o estado de saúde autorreferido em idosos. Estudo de base populacional que utilizou dados do Inquérito de Saúde de Campinas, São Paulo, Brasil (ISA-Camp 2008), com 1.418 idosos. Modelos de regressão linear foram usados para verificar a associação entre as escalas do SF36 versão 2 e os dois componentes de medida, com a duração do sono. Homens idosos que dormem 6 horas ou menos apresentam as menores médias dos escores do SF-36, comparando com os que dormem 7 a 8 horas, nos domínios de vitalidade e saúde mental. Todas as escalas apresentaram associação negativa com a duração do sono de 10 horas ou mais, exceto em dor. Nas mulheres, o tempo de sono $\leq 5$ horas se associou à pior situação nas escalas de saúde mental, aspectos emocionais e vitalidade. Saúde mental se associou negativamente com a duração do sono de 10 horas ou mais nessa população. A privação do sono e o excesso se associaram ao pior estado de saúde nos idosos, de maneira diferente entre os sexos, principalmente considerando o sono longo.

Qualidade de Vida; Sono; Saúde do Idoso; Nível de Saúde

\section{Contributors}

M. G. Lima participated in the conception of this study and drafting of this article and planned and carried out the statistical analysis. M. B. A. Barros participated in the design and conception of this study, in the statistical analysis and discussion and drafting of the manuscript. M. C. G. P. Alves participated in the statistical analysis and revision of the manuscript.

\section{Acknowledgements}

The authors are grateful to the CNPq (no 409747/2006-8) for financing this research (ISA-Camp 2008) and for the productivity scholarship provided to M. B. A. Barros and also to the Brazilian Ministry of Health and the Campinas Health Department for financial support to carry out the survey (Partnership Unicamp/Funcamp/SMS no 4300).

\section{References}

1. Ware JE, Kosinski M, Bjorner JB, Turner-Bowker DM, Gandek B, Maruish ME. User's manual for the SF-36v2 Health Survey. Lincoln: Quality Metric Inc.; 2007.

2. Lima MG, Barros MBA, César CLG, Carandina L, Goldbaum M. Impact of chronic disease on quality of life among the elderly in the state of São Paulo, Brazil: a population-based study. Rev Panam Salud Pública 2009; 25:314-21.

3. Alonso J, Ferrer M, Gandek B, Ware Jr. JE, Aaronson NK, Mosconi P, et al. Health-related quality of life associated with chronic conditions in eight countries: results from the International Quality of Life Assessment (IQOLA) Project. Qual Life Res 2004; 13:283-98.
4. Tsay SY, Chi LY, Lee CH, Chou P. Health-related quality of life as a predictor of mortality among community-dwelling older persons. Eur J Epidemiol 2007; 22:19-26.

5. Frybach DG, Dunham NC, Palta M, Hanmer J, Buechner J, Cherepanov D, et al. US norms for six generic health-related quality-of-life indexes from the National Health Measurement study. Med Care 2007; 45:1162-70.

6. Cappuccio FP, D’Elia L, Strazzullo P, Miller MA. Sleep duration and all-cause mortality: a systematic review and meta-analysis of prospective studies. Sleep 2010; 33:585-92. 
7. Ferrie JE, Shipley MJ, Cappuccio FP, Brunner E, Miller MA, Kumari M, et al. A prospective study of change in sleep duration: associations with mortality in the Withehall II Cohort. Sleep 2007; 30:1659-66.

8. Geib LTC, Cataldo Neto A, Wainberg R, Nunes ML. Sono e envelhecimento. Rev Psiquiatr Rio Gd Sul 2003; 25:453-65.

9. Nagai M, Hoshide S, Kario K. Sleep duration as a risk factor for cardiovascular disease: a review of a recent literature. Curr Cardiol Rev 2010; 6:54-61.

10. Mill JGV, Hoogendisk WJG, Vogelzangs N, Dyck RV, Penninx B. Insomnia and sleep duration in a large cohort of patients with major depressive disorder and anxiety disorders. J Clin Psychiatry 2010; 71:239-46.

11. Lima MG, Francisco PMSB, Barros M. Sleep duration pattern and chronic disease in Brazilian adults (ISACAMP 2008/2009). Sleep Med 2012; 13:139-44.

12. Patel SR, Malhotra A, White DP, Gottlieb DJ, Hu FB. Association between reduced sleep and weight gain in women. Am J Epidemiol 2006; 164:947-54.

13. Knutson KL. Sleep duration and cardiometabolic risk: a review of the epidemiologic evidence. Best Pract Res Clin Endocrinol Metab 2010; 24:731-43.

14. Birchler-Pedross A, Schröder CM, Münch M, Knoblauch V, Blatter K, Schnitzler-Sack C, et al. Subjective well-being is modulated by cicardian phase, sleep pressure, age and gender. J Biol Rhythm 2009; 24:232-42.

15. Akerstedt TA, Nilsson PM. Sleep as restitution: an introduction. J Int Med 2003; 254:6-12.

16. Ohayon MM. Interactions between sleep normative data and sociocultural characteristics in elderly. J Psychosom Res 2004; 56:479-86.

17. Tamakoshi A, Yoshiyki O. Self-reported sleep duration as predictor of all-cause mortality: results from the JACC study, Japan. Sleep 2004; 27:51-4.

18. Souza CS, Reimão R. Epidemiologia da insônia. Psicol Estud 2004; 9:3-7.

19. Campos HH, Bittencourt LRA, Haidar MA, Tufik S, Baracat EC. Prevalência de distúrbios do sono na pós-menopausa. Rev Bras Ginecol Obstet 2005; 27:731-6.

20. Burazeri G, Gofin J Kark JD. Over 8 hours of sleepmaker of increased mortality in Mediterranean population: follow-up population study. Croat Med J 2003; 44:193-8.

21. Ikehara S, Iso H, Date C, Kikuchi S, Watanabe Y, Wada Y, et al. Association of sleep duration with mortality from cardiovascular disease and other causes for Japanese men and women: the JACC Study. Sleep 2009; 32:259-301.

22. Krueger PM, Friedman EM. Sleep duration in the United States: a cross-sectional population-based Study. Am J Epidemiol 2009; 169:1052-63.

23. Hale L, Do P. Racial differences in self-reports of sleep duration in a population-based study. Sleep 2007; 30:1096-103.

24. Adams PF, Schoenborn CA. Health behaviors of adults: United States, 2002-04. National Center for Health Statistics. Vital Health Stat 10 2006; (230): $1-140$.
25. Faubel R, Lopez-Garcia E, Guallar-Castillón P, Balboa-Castillo T, Gutiérrez-Fisac JL, Banegas JR, et al. Sleep duration and health-related quality of life among older adults: a population-based cohort in Spain. Sleep 2009; 32:1059-68.

26. Steptoe A, Pearcey V, Wardle J. Sleep duration and health in young adults. Arch Intern Med 2006; 166:1689-92.

27. Pilcher JJ, Ginter DR, Sadowsky B. Sleep quality versus quantity: relationships between sleep and measures of health, well-being and sleepiness in college students. J Psychom Res 1997; 42:583-96.

28. Magee CA, Caputi P, Iverson DC. Relationships between self-rated health, quality of life and sleep duration in middle aged and elderly Australians. Sleep Med 2011; 12:346-50.

29. Winkelman JW, Redline S, Baldwin CM, Resnick HE, Newman AB, Gottlieb DJ. Polysomnographic and health-related quality of life correlates of restless leg syndrome in the sleep heart health study. Sleep 2009; 32:772-8.

30. Li J, Dong Q, Liu JJ, Yang LS, Ye DQ, Huang F. Sleep and quality of life among rural elderly in Anhui province. Zhonghua Liu Xing Bing Xue Za Zhi 2010; 31:405-8.

31. Arvidsson S, Arvidsson B, Fridlind B, Bergaman S. Factors promoting health-related quality of life in people with rheumatic diseases: a 12 month longitudinal study. BMC Musculoskelet Disord 2011; 12:102.

32. Ware JE, Kosinsk M. SF-36 physical \& mental health summary scales: a manual for users of version 1. 2nd Ed. Lincoln: Quality Metric Inc.; 2009.

33. Ciconelli RM, Ferraz MB, Santos W, Meinão I, Quaresma MR. Tradução para a língua portuguesa e validação do questionário genérico de avaliação de qualidade de vida SF-36 (Brasil SF-36). Rev Bras Reumatol 1999; 39:143-50.

34. Laguardia J, Campos MR, Travassos CM, Najar AL, Anjos LA, Vasconcellos MM. Psychometric evaluation sample of Brazilian households: results of the survey Pesquisa Dimensões Sociais das Desigualdades (PSDS), Brazil, 2008. Health Qual Life Outcomes 2011; 9:61.

35. Wyss K, Wagner AK, Whiting D, Mtasiwa DM, Tanner M, Gandek B, et al. Validation of the Kiswalhili version of the SF-36 Health Survey in a representative sample of an urban population in Tanzania. Qual Life Res 1999; 8:111-20.

36. Li L, Wang HM, Shen Y. Chinese SF-36 Health Survey: translation, cultural adaptation, validation and normalization. J Epidemiol Community Health 2003; 57:259-65.

37. Lima MG, Barros MBA, César CLG, Goldbaum M, Carandina L, Ciconelli RM. Health related quality of life among the elderly: a population-based study using SF-36 survey. Cad Saúde Pública 2009; 25:2159-67.

38. Lima MG, Barros MBA, Cesar CLG, Carandina L, Goldbaum M, Alves MCGP. Health-related behavior and quality of life among the elderly: a population-based study. Rev Saúde Pública 2011; 45: 845-93. 
39. Sabanayagam C, Shankar A. Sleep duration and cardiovascular disease: results from the National Health Interview Survey. Sleep 2010; 33:1037-42.

40. Castro-Costa E, Dewey ME, Ferri CP, Uchôa E, Firmo JOA, Rocha FL, et al. Association between sleep duration all-cause mortality in old age: 9-year follow-up of the Bambuí Cohort Study, Brazil. J Sleep Res 2011; 20:303-10.

41. Heslop P, Smith GD, Metcalfe C, Macleod J, Hart C. Sleep duration and mortality: The effect of short or long sleep duration on cardiovascular and allcause mortality in working men and women. Sleep Medicine 2002; 3:305-14.

42. Gottlieb DJ, Punjabi NM, Newman AB, Resnick HE, Redline S, Baldwin CM, et al. Association of sleep time with diabetes mellitus and impaired glucose tolerance. Arch Intern Med 2005; 165:863-8.

43. Hublin C, Partnen M, Koskenvuo M, Kaprio J. Sleep and mortality: a population-based 22 year followup study. Sleep 2007; 30:1245-53.

44. Gangwisch JE, Heymsfield SB, Boden-Albala B, Buijs RM, Kreier F, Opler MG, et al. Sleep duration associated with mortality in elderly, but not middle-aged, adults in a large US sample. Sleep 2008; 31:1087-96.

45. Cappuccio FP, Strazzullo P, D’Elia L, Miller MA. Quantity and quality of sleep and incidence of type 2 diabetes. Diabetes Care 2010; 33:414-20.
46. Veras RP. Crescimento da população idosa no Brasil: transformações e consequências na sociedade. Rev Saúde Pública 1987; 21:225-33.

47. Chien KL, Chen PC, Hsu HC, Su TC, Sung FC, Chen MF, et al. Habitual sleep duration and insomnia and the risk of cardiovascular events and all-cause death: report from a community-based cohort. Sleep 2010; 33:177-84.

48. Lauderdale DS, Knutson KL, Yan LL, Liu K, Rathouz PJ. Sleep duration: how well do self-reports reflect objective measures? The CARDIA Sleep Study. Epidemiology 2008; 19:838-45.

49. Lockley SW, Skene DJ Arendt J. Comparison between subjective and actigraphic measurement of sleep and sleep rhythms. J Sleep Res 1999; 8: 175-83.

50. Carlson P. Self-perceived health in East and West Europe: another European health divide. Soc Sci Med 1998; 46:1355-66.

51. Brock DW. The separatibility of health and wellbeing. In: Murray CJL, Joshua AS, Mathers CD, Lopez A, editors. Summary measures of population health. Concepts, ethics, measurement and applications. Geneva: World Health Organization; 2002. p. $115-20$.

Submitted on 24/Nov/2011

Final version resubmitted on 25/Apr/2012

Approved on 08/May/2012 